\title{
The Effect of Age on Glucose-Modulated Cerebral Agonal Glycolytic Rates Measured In Vivo by ${ }^{1}$ H NMR Spectroscopy
}

\author{
RONALD J. T. CORBETT, ABBOT R. LAPTOOK, JOAN I. RULEY, AND DAMIAN GARCIA
}

Ralph Rogers and Mary Nell Magnetic Resonance Center, Department of Radiology [R.J.T.C.] and Pediatrics [A.L.R., J.I.R., D.G.], University of Texas Southwestern Medical Center, Dallas. Texas 75235-9085

\begin{abstract}
The purpose of this study was to investigate the effect of plasma glucose concentration on cerebral agonal glycolytic rates in piglets of different ages. Twentyfour piglets were divided into four different age groups corresponding to $113,121,128$, and $145 \mathrm{~d}$ postconception (normal gestation $=115 \mathrm{~d}$ ). For each group the agonal glycolytic rate was measured by monitoring the rate of cerebral lactate accumulation after total ischemia. Ischemia was induced by cardiac arrest, and the rate of lactate formation was measured in vivo using proton nuclear magnetic resonance spectroscopy. Before cardiac arrest, the blood plasma glucose concentration for individual piglets was adjusted to a specific value in the range $1-30 \mathrm{mM}$. The dependence of agonal glycolytic rate upon blood glucose concentration was analyzed for each age group, using the Michaelis-Menten equation to evaluate $V_{\max }$, the maximal rate of glucose utilization, and $\mathrm{Km}$ the concentration of plasma glucose at which the half maximal rate of utilization occurs. $V_{\max }$ for the two youngest age groups of piglets had significantly different $(p<0.05)$ values compared with each other $(1.38 \pm 0.17$ and $1.92 \pm 0.64 \mu \mathrm{mol}$. $\mathrm{g}^{-1} \cdot \mathrm{min}^{-1}$, respectively) and with the two older groups of animals $\left(2.99 \pm 0.52\right.$ and $3.42 \pm 0.65 \mu \mathrm{mol} \cdot \mathrm{g}^{-1} \cdot \mathrm{min}^{-1}$, respectively). The $\mathrm{Km}$ values determined for the two youngest age groups $(0.79 \pm 0.70$ and $1.79 \pm 0.33 \mathrm{mM}$, respectively) also were significantly lower than for the two older age groups $(4.96 \pm 2.90$ and $4.82 \pm 2.96 \mathrm{mM}$, respectively). We conclude that throughout the first 2 wk of life there are marked increases in the cerebral glycolytic capacity. It follows, therefore, that rates of lactate formation in newborns are not as strongly accelerated by increased blood glucose compared with older piglets. During combined hyperglycemia and severe ischemia, newborns will not be exposed to harmful levels of cerebral lactate as rapidly as 2- to 4-wk-old piglets. However, despite the differences in glycolytic rates, all four age groups showed similar potentials to generate high cerebral lactate concentrations. Furthermore, the final brain lactate concentration showed the same linear correlation with preischemia plasma glucose concentration for all four age groups. The implications of this study are that piglets of any age have the same potential to generate high concentrations of brain lactate, although newborns will reach this level more slowly than older animals. (Pediatr Res 30: 579-586, 1991)
\end{abstract}

Received March 21, 1991; accepted July 16, 1991.

Correspondence and reprint requests: Ron Corbett, Department of Radiology, 5801 Forest Park Road, University of Texas Southwestern Medical Center, Dallas TX 75235-9085.

Supported by 90 G-075 Grant-in-Aid awarded by the American Heart Association Texas Affiliate, BRSG 2 S07 RR 07175-13 awarded by the Biomedical Research Support Grant Program, Division of Research Resources NIH, and Southwestern In Vivo Biotechnology Resource Facility Grant 5-P41-RR02584.

\begin{abstract}
Abbreviations
AGR, initial agonal glycolytic rate

[glucose $]_{\text {plasma, }}$ arterial blood plasma glucose concentration

${ }^{1} \mathrm{H}$ NMR, proton nuclear magnetic resonance

$k$, first order rate constant for lactate accumulation

$\mathrm{Km}$, blood plasma glucose concentration at which the glycolytic rate is half maximal

[lactate] $]_{\text {final }}$, final postmortem brain lactate concentration

MAP, mean arterial blood pressure

$\mathrm{V}_{\text {max }}$, maximum agonal glycolytic rate
\end{abstract}

The role of glucose status in immature animals exposed to hypoxic-ischemia insults is controversial (1). In adults, an elevated blood glucose concentration during cerebral ischemia is detrimental to the recovery of normal brain function and structure. A detrimental role for elevated glucose is based on the presumption that there is excessive lactate production during hyperglycemic hypoxia-ischemia compared with when glucose is not elevated. Support for this comes from studies of juvenile monkeys $(2)$ and adult rats $(3,4)$ that were made hyperglycemic before or during ischemia or anoxia and showed increased morphologic brain damage and poorer clinical recovery compared with normoglycemic controls. Hyperglycemic animals generate higher levels of brain lactate compared with normoglycemic animals, and brain lactate concentrations in excess of $20 \mu \mathrm{mol}$. $\mathrm{g}^{-1}$ appear to represent a threshold for extensive brain edema, tissue necrosis, and higher mortality (5). Irreversible damage to the brain is enhanced by increased intracellular brain lactic acidosis (6). Lactic acidosis occurs because of elevated rates of anaerobic glycolysis, with glucose being converted to lactate and concurrent production of $\mathrm{H}^{+}(5,7)$. Several clinical studies have reported that adult stroke patients with elevated blood glucose have a poorer prognosis than their normoglycemic counterparts (8).

In contrast, administration of glucose improves the "survival response" of newborn rodents exposed to ischemic or anoxic insults (9). A longer survival response was initially attributed to sustained brain energy metabolite levels (10). However, separate studies comparing glucose-supplemented versus saline-infused 7 . d-old rats revealed that both groups had the same extent of depletion in high-energy phosphate reserves, brain lactate accumulation $\left(15-19 \mu \mathrm{mol} \cdot \mathrm{g}^{-1}\right)$, and neuropathologic evidence of brain damage when exposed to a combination of hypoxia-ischemia for up to $2 \mathrm{~h}(11,12)$. The latter results lead to the hypothesis that factors such as the low glucose transport across the bloodbrain barrier or low glycolytic rates in immature brain limit the severity of cerebral lactic-acidosis during hypoxia-ischemia (12). This in turn has formed the basis of a proposal for human clinical tests of the benefits of maternal glucose supplementation during 
labor and delivery (13). We believe that such a proposal deserves further testing with alternative species before it is applied to human infants. Recent studies in this laboratory indicate that piglets $(8 \pm 3 \mathrm{~d}$ old $)$ generate substantial levels of lactic acidosis during partial ischemia comparable to that seen in adult animals of other species (14). In addition, the degree of brain acidosis was strongly correlated with the plasma glucose concentration during partial ischemia (15). It is unknown whether or not differences in brain lactate accumulation in piglets and rodents occur because of brain maturational factors, differences in experimental protocols to induce hypoxia-ischemia, or species differences in brain glucose transport or utilization capabilities unrelated to brain maturation.

In this study we have used in vivo ${ }^{1} \mathrm{H}$ NMR spectroscopy to determine to what extent the brain lactate accumulation during total ischemia changes in piglets of different ages. The specific questions addressed are: 1) Does cerebral glycolytic rate increase as a function of age in piglets? 2) What is the relationship between blood glucose concentration and cerebral glycolytic rate in animals of different ages? 3) Is cerebral lactate accumulation in newborn piglets less than that found in older piglets?

\section{MATERIALS AND METHODS}

Experimental protocol. The surgical procedures and experimental protocol were approved by the U. T. Southwestern Medical Center Institutional Review Board for Animal Research. A total of 24 miniature swine (Sinclair strain) from eight different litters were studied. The piglets were divided into four groups ranging in postconceptual age from 111 to $117 \mathrm{~d}$ (group 1), 120 to $122 \mathrm{~d}$ (group 2), 126 to $134 \mathrm{~d}$ (group 3), and 141 to $151 \mathrm{~d}$ (group 4). Normal term gestation is $115 \mathrm{~d}$ for this strain of pigs. On the day of the study, an animal was surgically prepared, placed in the magnet, and allowed to attain stable blood gas readings during a 1 -h period before collecting control data. Control data consisted of a ${ }^{1} \mathrm{H}$ NMR spectrum and arterial blood gas and substrate measurements, to assess baseline brain lactate levels and systemic physiologic status, respectively. Next, i.v. infusions of glucose $(0-30 \mathrm{mg} / \mathrm{kg} / \mathrm{min})$ or bolus injection of insulin $(1-2 \mathrm{IU} / \mathrm{kg} \text { ) was performed to adjust the [glucose }]_{\text {plasma }}$ of individual piglets to a predesignated value in the range 1 to 30 $\mathrm{mM}$. Preliminary trials on separate animals indicate that the most rapid change in [glucose] plasma occurs during the first 10-20 min of the adjustment period. In the present study, after $20-30$ min, samples of blood were obtained at 5- to 10 -min intervals

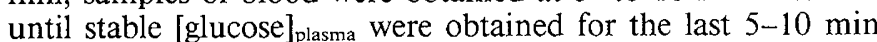
before cardiac arrest. There were no differences noted in the stability of [glucose $]_{\text {plasma }}$ for any age group. Only [glucose $]_{\text {plasma }}$ measurements made $1 \mathrm{~min}$ before cardiac arrest were used in calculations to quantify the relationship between [glucose] $]_{\text {plasma }}$ and cerebral metabolism. When the desired [glucose] $]_{\text {plasma }}$ was reached, an additional cerebral ${ }^{1} \mathrm{H}$ NMR spectrum and arterial blood samples were collected. Complete cerebral ischemia was then initiated via cardiac arrest, induced by an i.v. injection of 4 $\mathrm{mL}$ of $4 \mathrm{M} \mathrm{KCl}$ directly to the heart. The rate of lactate accumulation was measured by collecting 50 individual ${ }^{1} \mathrm{H}$ NMR spectra every $0.6 \mathrm{~min}$ for $30 \mathrm{~min}$, starting $1 \mathrm{~min}$ before cardiac arrest. After 30 min NMR data collection was ceased, and the animal was removed from the magnet. The portion of the cerebral cortex immediately below the NMR coil was removed and stored at $-70^{\circ} \mathrm{C}$ for subsequent analysis of [lactate $]_{\text {final }}$.

Animal preparation. In two litters studied, birth was initiated after 110 and $114 \mathrm{~d}$ gestation, respectively, via prostaglandin induced labor (16). Two intramuscular injections of F2 $\alpha$-prostaglandin (10 mg/kg lutalyse; Upjohn, Kalamazoo, MI) separated by $12 \mathrm{~h}$ induced labor within $24 \mathrm{~h}$ of the first injection. Piglets from other litters were studied after spontaneous term delivery (114-116 d). On the day of the study, piglets were premedicated with ketamine $(10 \mathrm{mg} / \mathrm{kg}$, intramuscular), and the sites of surgery were infiltrated with $1 \%$ xylocaine for local anesthesia. The piglet was then rapidly tracheotomized and ventilated with $70: 30$ $\mathrm{N}_{2} \mathrm{O}: \mathrm{O}_{2}$ (small animal respirator; Harvard Apparatus Co., Inc., S. Natick, MA). Intravascular catheters were placed in the abdominal aorta and inferior vena cava via a femoral artery and vein, respectively. Next d-tubcurarine $\mathrm{Cl}(0.10 \mathrm{mg} / \mathrm{kg})$ and nalbuphine $(0.15 \mathrm{mg} / \mathrm{kg})$ were administered i.v. for muscle relaxation and analgesia, respectively. Skin overlying the skull was retracted so that the NMR radiofrequency coil rested directly on the skull. After surgery the animal was then transported to the magnet and stabilized for $1 \mathrm{~h}$ before commencing in vivo NMR measurements. A second injection of nalbuphine was given 15 min before initiating cardiac arrest.

NMR spectroscopy. ${ }^{1} \mathrm{H}$ NMR spectroscopy was performed using a General Electric CSI system (Fremont, CA) and $40-\mathrm{cm}$ diameter bore Oxford superconducting magnet (Oxford, UK) operating at a magnetic field strength of 4.7 Tesla. The ${ }^{1} \mathrm{H}$ NMR signal from brain was measured using a two-turn radiofrequency coil (outer coil dimensions: $5 \times 3 \mathrm{~cm}$ ) tuned to $200 \mathrm{MHz}$ using the circuit design described by Gonnella and Silverman (17). To measure the $\beta$-lactate ${ }^{1} \mathrm{H}$ signal, it is necessary to suppress interfering signals from water and lipids by the use of a spin echo pulse sequence with binomial pulses $(14,18)$. Thus, ${ }^{1} \mathrm{H}$ NMR data was collected using a $\overline{1} 3 \overline{3} 1-\tau-\overline{2} 6 \overline{6} 2-\tau-$ Ac, spin echo pulse sequence, where 1 corresponds to the first portion of a binomial pulse equal to $1 / 8$ of the $90^{\circ}$ pulse width; the other pulses are multiples of this and the bar indicates phase inversion (19). The prepulse delay time was $1 \mathrm{~s}$ and $\tau$, the delay time for echo formation, was $150 \mathrm{~ms}$. The accumulated free induction decay ( 16 transients collected every $36 \mathrm{~s}$ ) was processed by applying direct current offset baseline correction, a $10-\mathrm{Hz}$ exponential apodization function, Fourier transformation, and zero order phasing. The phase angle applied was determined from the setting that gave the maximal positive peak for the final postmortem $\beta$ lactate NMR spectrum. The resulting ${ }^{1} \mathrm{H}$ NMR spectra still contain nonlactate signal; to remove this, the control spectrum was subtracted from all subsequent spectra collected during ischemia to yield difference spectra corresponding to the change in cerebral lactate concentration after cardiac arrest. The validity of this method for measuring changes in brain lactate concentration was established through tests on phantoms and in vivo brain tissue in this lab $(14,20)$ and elsewhere $(18,21)$. Previous experiments with piglet skull phantoms indicate that for the coil diameter and excitation pulse lengths used, the majority of the NMR signal is obtained from cortical gray and white matter within $1.5 \mathrm{~cm}$ of the coil. The relationship between the in vivo NMR lactate signal height and brain lactate concentration was established by using the postmortem brain lactate NMR signal and [lactate] final as a calibration factor. As in previous studies using ${ }^{1} \mathrm{H}$ NMR, the procedure to derive brain lactate concentrations from the in vivo ${ }^{1} \mathrm{H}$ NMR spectra collected during ischemia assumes that the spin-spin and spin-lattice relaxation times of the $\beta$-lactate ${ }^{1} \mathrm{H}$ do not change during ischemia and the postmortem measurements. There did not appear to be a significant change in relaxation times between control and postmortem, inasmuch as control brain lactate levels derived from the postmortem calibration of the $\beta$-lactate ${ }^{1} \mathrm{H}$ NMR signal are in good agreement with a brain lactate concentration of $1.53 \pm 0.03$ $\mu \mathrm{mol} \cdot \mathrm{g}^{-1}$ (wet weight), measured from perchloric acid extracts of brain tissue obtained at control (20). We examined the line width of the lactate peak from the time course ${ }^{1} \mathrm{H}$ NMR difference spectra for 10 animals spanning the full age range studied. There were no significant correlations between line width and the time at which the spectrum was obtained, suggesting that the apparent spin-spin relaxation time remained constant.

Physiologic monitoring and biochemical measurements. MAP and heart rate were measured via the catheter in the abdominal aorta using a pressure transducer (Gould Inc., Cleveland, $\mathrm{OH}$ ) and a polygraph (Coulbourn Instruments Inc., Lehigh Valley, PA). The catheter in the abdominal aorta was also used to obtain blood for monitoring arterial blood $\mathrm{pH}$, gases, lactate, glucose, 
and hematocrit. The catheter in the inferior vena cava was used for the administration of nalbuphine, glucose, insulin, and $4 \mathrm{M}$ $\mathrm{KCl}$. Arterial blood $\mathrm{pH}, \mathrm{PCO}_{2}$, and $\mathrm{PO}_{2}$ were measured from a $200-\mu \mathrm{L}$ sample using a Corning 165 blood gas analyzer. Plasma lactate concentration was measured using the lactate dehydrogenase assay after deproteinization of $200 \mu \mathrm{L}$ of plasma with $8 \%$ perchloric acid and centrifugation for $1 \mathrm{~min}$ at $1500 \times g$. Plasma glucose was determined by the glucose oxidase/peroxidase assay after deproteinization of $50 \mu \mathrm{L}$ of plasma with $2 \%$ perchloric acid and centrifugation. Polygraph traces of heart rate and MAP were recorded continuously during the experiments, and blood samples were drawn at the midpoint of the two preischemia NMR data collection periods.

Frozen postmortem cortical brain samples (5-10 g/piglet) were ground into a powder and mixed thoroughly to ensure a homogeneous sample representative of the entire region of brain measured by the NMR radiofrequency coil. Brain tissue lactate concentrations were determined using the lactate dehydrogenase enzymatic assay of the neutralized aqueous portion from $0.5 \mathrm{~g}$ of brain powder, homogenized and extracted in $5 \%$ perchloric acid (22).

Data analysis. All statistical tests and regression fits were performed using SPSS/PC (Version 3.1; Statistical Package for the Social Sciences Inc., Chicago, IL), loaded on an AST premium/286 personal computer (AST Research Inc., Irvine, CA).

The first order rate constant for lactate production $(k)$ was determined by analysis of the initial change in brain lactate concentrations ([lactate $]_{\mathrm{t}}$ ) measured at different times $(\mathrm{t})$ up to 5 min after cardiac arrest using the following equation:

$$
[\text { lactate }]_{\mathrm{t}}=[\text { lactate }]_{\text {final }} \cdot[1-\exp (-\mathrm{kt})]
$$

where [lactate $]_{\text {final }}$ is equal to the postmortem brain lactate concentration minus control brain lactate concentration $(1.5 \mu \mathrm{mol}$. $\left.\mathrm{g}^{-1}\right)$, inasmuch as the lactate signal at control is not represented in the ${ }^{1} \mathrm{H}$ NMR difference spectra that we use to measure lactate accumulation. Nonlinear regression analysis was performed to obtain the best estimate and SD of the rate constant for lactate production, k. Preliminary tests with simulated data, with pseudo random noise added to [lactate $]_{t}$, suggested that using statistically weighted data (with weighting proportional to the signal to noise ratio of the ${ }^{1} \mathrm{H}$ NMR signal used to calculate [lactate] $]_{\mathrm{t}}$ ) did not substantially improve the accuracy of the best estimated value of $\mathrm{k}$ and, therefore, weighing was not used in the analysis of data.

The initial AGR equals the maximum rate of lactate production (i.e. [lactate] $]_{\text {final }}$ multiplied by $\mathrm{k}$ ) divided by 2 , inasmuch as 2 lactate molecules are produced per molecule of glucose consumed during glycolysis:

$$
\begin{aligned}
\mathrm{AGR}=\mathrm{d}[\text { glucose }] / \mathrm{dt}=(\mathrm{d}[\text { lactate }] / \mathrm{dt}) / 2 & \\
& =\left([\text { lactate }]_{\text {final }} \mathrm{k}\right) / 2
\end{aligned}
$$

AGR was related to the substrate concentration, [glucose $]_{\text {plasma }}$, via the Michaelis-Menten equation:

$$
\begin{aligned}
A G R=(\mathrm{d}[\text { glucose }] / \mathrm{dt})_{\text {initial }} & \\
& =\left(\mathrm{V}_{\text {max }}[\text { glucose }]_{\text {plasma }}\right) /\left([\text { glucose }]_{\text {plasma }}+\mathrm{Km}\right)
\end{aligned}
$$

$\mathrm{V}_{\max }$ corresponds to the [glucose] $]_{\text {plasma }}$ where AGR shows no further increases and represents the maximal cerebral glycolytic rate with respect to blood glucose concentration. $\mathrm{Km}$ is the apparent Michaelis-Menten constant for glucose corresponding to the [glucose] $]_{\text {plasma }}$ where half maximal reaction velocity is reached. Nonlinear regression analysis was performed to obtain best fit estimates of the parameters $\mathrm{V}_{\max }$ and $\mathrm{Km}$ for each age group of piglets. The superior accuracy of parameters estimated using nonlinear analysis compared with transformed linear models is well established $(23,24)$.

Tests for group differences were made by a one-way analysis of variance using Duncan's multiple comparison test (25) to identify statistically significant differences $(p<0.05)$ between specific pairs of means.

\section{RESULTS}

The mean control physiologic values for the four age groups of piglets are summarized in Table 1. Significant increases in body weight, hematocrit, and MAP occurred with increasing age. The two youngest age groups of piglets had slightly higher blood lactate concentrations than the two oldest groups. Newborn piglets (group 1) had a lower [glucose] $]_{\text {plasma }}$ than the three older groups of animals. The lower mean arterial $\mathrm{pH}$ for group 1 can be totally accounted for by the elevated $\mathrm{PCO}_{2}$ observed for some animals in this group. The latter reflects increased difficulties in ventilating younger piglets because of partial endotracheal tube obstruction in some animals. Overall we judge the difference in blood gases in group 1 compared with the other three groups to be small and to have little effect on cerebral glycolytic rates during ischemia (see Discussion).

After the 30 -min interval during which time [glucose] $]_{\text {plasma }}$ was adjusted to a value in the range 1 to $30 \mathrm{mM}$, a second series of physiologic measurements and a ${ }^{1} \mathrm{H}$ NMR spectrum were collected for each animal. With the exception of [glucose $]_{\text {plasma }}$, there were no significant changes in group means in any of the physiologic variables, compared with the first measurement shown in Table 1 . The difference ${ }^{1} \mathrm{H}$ NMR spectra revealed no visible changes in brain lactate comparing pre- to post-[glucose $]_{\text {plasma }}$ alterations. After the injection of $\mathrm{KCl}$, the heart rate dropped to zero within one or two beats, with a concurrent drop in blood pressure. Thus, the protocol resulted in a well-defined time point at which total cerebral ischemia was initiated. In five piglets (ranging in age from 2 to $14 \mathrm{~d}$ old), rectal temperature was monitored throughout the $30-\mathrm{min}$ protocol. Before cardiac arrest, the rectal temperatures ranged from 37.8 to $38.3^{\circ} \mathrm{C}$ in the five animals. For each animal, the postmortem temperature measured after $30 \mathrm{~min}$ differed by less than $1^{\circ} \mathrm{C}$ compared with control temperature. No age-related trends were noted. The presence of the temperature probe and extension cable coming out of the magnet had no effect on the quality of the ${ }^{1} \mathrm{H}$ NMR data collected for these animals.

Representative in vivo ${ }^{1} \mathrm{H}$ NMR spectra for an animal from group 1 are shown in Figure 1. The NMR pulse sequence produced excellent suppression of the ${ }^{1} \mathrm{H}$ NMR signal from water, as indicated by the absence of signal at $4.8 \mathrm{ppm}$. The most prominent peaks in the control ${ }^{1} \mathrm{H}$ spectrum (inset $A$ ) are from 2.0 to $1.0 \mathrm{ppm}$, corresponding to $\mathrm{N}$-acetyl aspartate, lipid, and lactate (17). In the 30 -min postarrest spectrum (inset $B$ ), a large signal appears at $1.4 \mathrm{ppm}$, corresponding to the $\mathrm{B}$ protons of lactate. No peaks other than the one corresponding to lactate were apparent in the difference spectrum (inset $C$ ). Figure 1 also displays the time course of changes in brain lactate levels as measured from ${ }^{1} \mathrm{H}$ NMR difference spectra, taken at selected time intervals after cardiac arrest. There was a rapid increase in brain lactate over the first $5 \mathrm{~min}$ (circulatory arrest at time $=0$ ). No significant changes in the intensity of the lactate signal were observed in the final 5 min of ${ }^{1} \mathrm{H}$ NMR data accumulation for any of the piglets studied. Thus a 30-min study interval appeared to be sufficient duration to allow for the maximum accumulation of brain lactate.

The kinetics of lactate formation and the modelling of these data using equation 1 are displayed in Figure 2 for four animals from age group 2 . It is evident that piglets attain different [lactate] final values depending upon the [glucose] $]_{\text {plasma }}$ at the time of cardiac arrest. Nonlinear regression analysis using the first $5 \mathrm{~min}$ of lactate versus time data sets for each animal resulted in best fit $\mathrm{k}$ values that ranged from approximately 0.1 to $0.5 \mathrm{~min}^{-1}$. The standard error for the best fit $\mathrm{k}$ values ranged from 2.5 to $10 \%$. There was no correlation between the magnitude of $\mathrm{k}$ and the size of the standard error. We considered the possibility that there were slow changes in brain lactate from 5 to 20 min that 
Table 1. Comparison of physiologic data for different age groups of piglets (mean $\pm S D)^{*}$

\begin{tabular}{|c|c|c|c|c|}
\hline & Group $1(n=7)$ & Group $2(n=5)$ & Group $3(n=6)$ & Group $4(n=6)$ \\
\hline Age (d) & $113 \pm 3^{2.3 .4}$ & $121 \pm 1^{1,3,4}$ & $128 \pm 3^{1,2,4}$ & $145 \pm 4^{1,2,4}$ \\
\hline Weight $(\mathrm{kg})$ & $0.8 \pm 0.2^{3.4}$ & $1.8 \pm 0.1^{4}$ & $2.7 \pm 0.4^{1,4}$ & $4.3 \pm 1.8^{1,2,3}$ \\
\hline [glucose $]_{\text {plasma }}(\mathrm{mM})$ & $3.6 \pm 1.2^{2,3.4}$ & $6.9 \pm 0.5^{1}$ & $7.5 \pm 2.1^{1}$ & $6.8 \pm 1.8^{1}$ \\
\hline [lactate] $]_{\text {plasma }}(\mathrm{mM})$ & $2.2 \pm 0.9^{3,4}$ & $2.3 \pm 0.9^{3}$ & $1.1 \pm 0.4^{1,2}$ & $1.4 \pm 0.6^{1}$ \\
\hline $\mathrm{pH}$ & $7.32 \pm 0.08^{4}$ & $7.37 \pm 0.07$ & $7.39 \pm 0.05$ & $7.43 \pm 0.05^{1}$ \\
\hline $\mathrm{PCO}_{2}(\mathrm{kPa})$ & $6.1 \pm 1.2^{2,3,4}$ & $4.7 \pm 0.4^{1}$ & $4.9 \pm 0.4^{1}$ & $4.8 \pm 0.4^{1}$ \\
\hline $\mathrm{PO}_{2}(\mathrm{kPa})$ & $14.0 \pm 2.7^{3,4}$ & $12.1 \pm 6.1^{3,4}$ & $19.7 \pm 6.1^{1,2}$ & $20.4 \pm 2.5^{1.2}$ \\
\hline HCT (volume \%) & $30 \pm 2^{2,4}$ & $34 \pm 2^{1}$ & $33 \pm 4^{4}$ & $36 \pm 3^{1,3}$ \\
\hline HR (beat/min) & $204 \pm 34^{2,3}$ & $276 \pm 36^{1.4}$ & $258 \pm 43^{1,4}$ & $198 \pm 52^{2,3}$ \\
\hline $\mathrm{MAP}(\mathrm{mm} \mathrm{Hg})$ & $61 \pm 13^{3,4}$ & $71 \pm 21^{4}$ & $85 \pm 6^{1}$ & $91 \pm 16^{1,2}$ \\
\hline
\end{tabular}

* [lactate $_{\text {plasma }}$, plasma lactate concentration; HCT, hematocrit; HR, heart rate. The superscripts $1,2,3$, and 4 refer to the groups means that are significantly different than the group listed in the column heading at $p<0.05$ using the Duncan multiple comparison test. For example, group 1 has a significantly different plasma glucose concentration compared to groups 2,3 , and 4 .

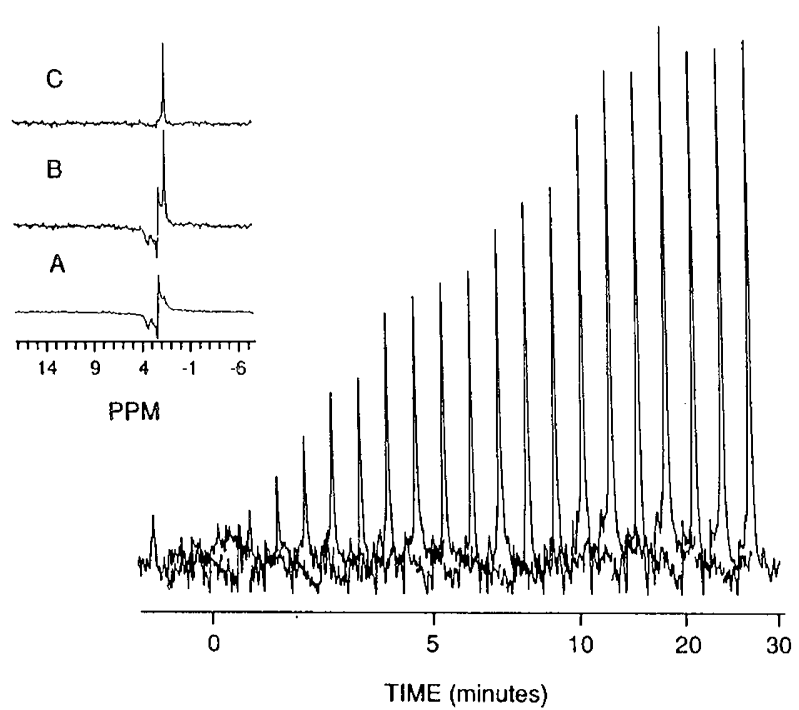

Fig. 1. The time course of change in 'H NMR difference spectra from piglet brain during total ischemia. The series of difference spectra were obtained from a piglet $117 \mathrm{~d}$ after conception, -1 to 29 min after total cerebral ischemia was initiated via cardiac arrest (time $=0$ ). Each spectrum from the region 3 to $0 \mathrm{ppm}$ is displayed; each spectrum was acquired at the times indicated on the horizontal axis (cardiac arrest at time $=0$ ). The vertical dimension corresponds to ${ }^{1} \mathrm{H}$ NMR signal amplitude, which is proportional to brain lactate concentration. After 40 min, a brain tissue sample was removed from the animal and later determined to contain lactate at a concentration of $23.6 \mu \mathrm{mol} \cdot \mathrm{g}^{-1}$. The inset figure shows the original spectra used to calculate a difference spectrum $\{A$, control sum of 160 transients, $B$, ischemia at $29 \mathrm{~min}$, sum of 16 transients; $C$, difference spectrum $[\mathrm{B}-(0.1 \times \mathrm{A})]\}$. The signal to noise ratio for the lactate peak in the difference spectrum is $42: 1$.

could affect the values of $k$ or [lactate] $]_{\text {final }}$ estimated from the NMR data. As an additional internal check that [lactate] $]_{\text {final }}$ were indeed attained within $30 \mathrm{~min}$, nonlinear regression analysis using the first $20 \mathrm{~min}$ of data was performed. A form of equation 1 was used in which both $\mathrm{k}$ and [lactate] $]_{\text {final }}$ were adjustable parameters. The best fit [lactate] final values were not significantly different than [lactate] $]_{\text {final }}$ values determined from the $45-\mathrm{min}$ postmortem enzymatic analysis of brain tissue extracts. The resulting best fit $\mathrm{k}$ values were on average only $6 \%$ greater than $\mathrm{k}$ calculated using only the first $5 \mathrm{~min}$ of data. As a check of the robustness of the best fit $\mathrm{k}$ values calculated from the first $5 \mathrm{~min}$ of data, several different initial seed values for $\mathrm{k}$ (range 0.1 to 0.5 ), were used for the nonlinear regression analysis of selected data sets. In all cases the regression analysis converged to a best fit result with identical $\mathrm{k}$ values.

The rate constant for lactate accumulation was modulated by [glucose $]_{\text {plasma }}$ in a distinctive fashion for each age group (Fig. 3).

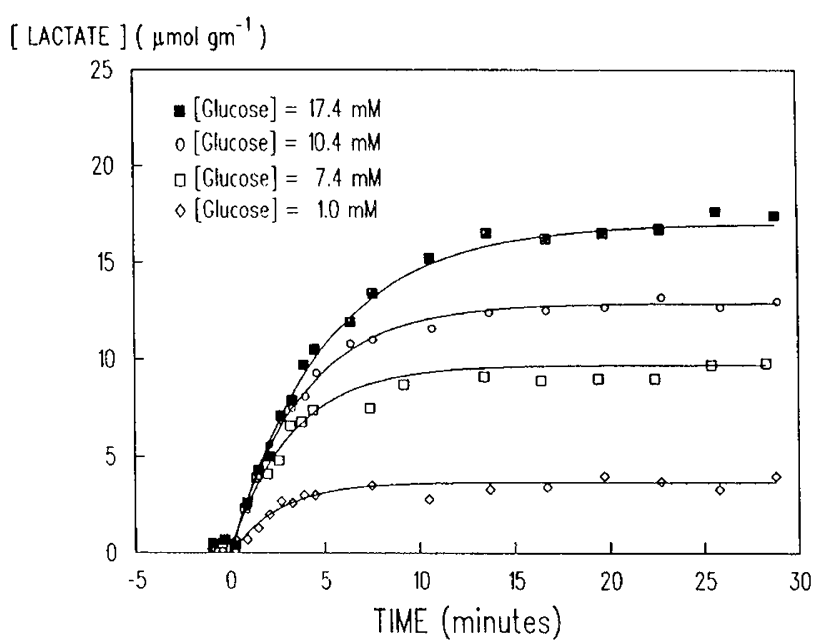

Fig. 2. Rates of lactate information after total ischemia. Plots of the change in lactate concentration ( $\Delta$ [lactate]) $v s$ time are shown for four piglets in age group 2 (120 to $122 \mathrm{~d}$ postconception). The blood plasma glucose concentration ([Glucose]) for individual piglets immediately before cardiac arrest (time $=0$ ) is indicated by the value in the figure. The solid lines correspond to the best fit by nonlinear regression to the data using equation 1 (Materials and Methods). The first order rate constant $\mathrm{k}=0.20 \pm 0.004,0.26 \pm 0.006,0.31 \pm 0.01$, and $0.39 \pm 0.02$ $\mathrm{min}^{-1}$ (best fit $\pm \mathrm{SEM}$ ) for animals with [Glucose] values of $17.4,10.4$, 7.4 , and $1.0 \mathrm{mM}$, respectively.

Significant negative linear correlations $(p<0.05)$ were present between $\mathrm{k}$ and [glucose] $]_{\text {plasma }}\left(r^{2}\right.$ range from 0.61 to 0.81 ), with the exception of the oldest group (group $4, r^{2}=0.01$ ). The slopes from linear regression for groups 1,2, and 3 were all significantly different from group 4, but not from each other. The intercept for group 1 was significantly lower than the intercept for groups 2,3 , and 4.

Despite the trend for a lower rate constant of lactate accumulation for younger piglets, the potential for each age group to generate similar maximum terminal brain lactate concentrations was remarkably similar (Fig. 4). Linear regression analysis of [lactate] $]_{\text {final }}$ versus the preischemia [glucose] $]_{\text {plasma }}$ for each age group revealed positive correlations ( $r^{2}$ range: 0.53 to 0.88 ) with no significant difference in slopes between groups; the intercepts for groups 1 and 4 were slightly higher than those for groups 2 and 3.

The initial AGR, calculated using equation 2, showed a strong dependence on glucose for all four age groups (Fig. 5). Nonlinear regression analysis of $A G R$ versus [glucose] plasma using equation 3 revealed substantial differences in $\mathrm{V}_{\max }$ and $\mathrm{Km}$ values between age groups with a significant trend for higher $V_{\max }$ and $\mathrm{Km}$ values in older piglets (Table 2). The two youngest age groups (groups 


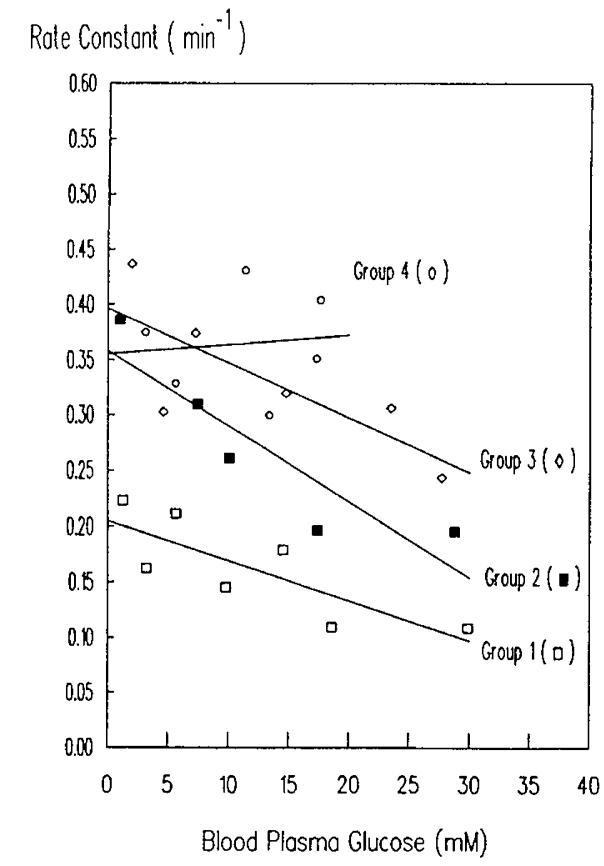

Fig. 3. The relationship between the rate constant for lactate accumulation (see Materials and Methods, equation 1) and blood plasma glucose concentration for different age groups of piglets. Different symbols are used to represent animals in each of the four age groups (Table 1) as defined in the figure. The solid lines represent the best fit by linear regression analysis for each of the four age groups. Slopes $( \pm \mathrm{SD})$ for groups 1 to 4 are $-0.0036 \pm 0.0013,-0.0068 \pm 0.0022,-0.0049 \pm$ 0.0022 , and $0.0009 \pm 0.0044 \mathrm{~min}^{-1} / \mathrm{mM}$, respectively. Intercepts for groups 1 to 4 are $0.20 \pm 0.03,0.36 \pm 0.04,0.40 \pm 0.05$, and $0.36 \pm 0.06$ $\min ^{-1}$, respectively.

1 and 2) both had significantly lower $V_{\max }$ and $\mathrm{Km}$ values compared with groups 3 and 4 . Neither $\mathrm{Km}$ nor $\mathrm{V}_{\max }$ differed between groups 3 and 4 . $V_{\max }$ for group 1 was significantly lower than $\mathrm{V}_{\max }$ for group 2 .

\section{DISCUSSION}

The unique capabilities of in vivo ${ }^{1} \mathrm{H}$ NMR have allowed new information to be gained concerning the ability of blood glucose to modulate the brain metabolic response to cardiovascular failure. It is worth noting that our ability to perform repetitive measurements of the change in cerebral lactate concentration within a single animal made it feasible to obtain kinetic information that otherwise would require the study and averaging of data from multiple animals. It is this ability that has allowed us to examine the effect of glucose on AGR using a relatively small number of animals compared with previous non-NMR studies.

The mean arterial blood $\mathrm{PCO}_{2}$ was higher for piglets in group $1(6.1 \mathrm{kPa})$ compared with the group means for older animals (4.7-4.9 kPa; see Table 1). Because acute hyperglycemia has been shown to inhibit glycolysis (26), the possibility exists that the low AGR values in group 1 are at least in part a reflection of hypercapnia. There are two reasons why we believe that this effect is negligibly small. First, previous studies have shown that severe hypercapnia (i.e. inhalation of $20 \% \mathrm{CO}_{2}$ ) is required for $50 \%$ inhibition of the cerebral metabolic rate for glucose utilization (26). The impact of mild hypercapnia on the rate of glucose utilization should be proportionally smaller. Second, it is thought that the mechanism of inhibition involves decreased activity of phosphofructokinase, due to hypercapnic acidosis (26). However, the change in intracellular brain $\mathrm{pH}$, measured in vivo using ${ }^{31} \mathrm{P} \mathrm{NMR}$, is negligible for piglets over a $\mathrm{PCO}_{2}$ range of 4.8 to $6.1 \mathrm{kPa}(27)$. It therefore seems unlikely that the

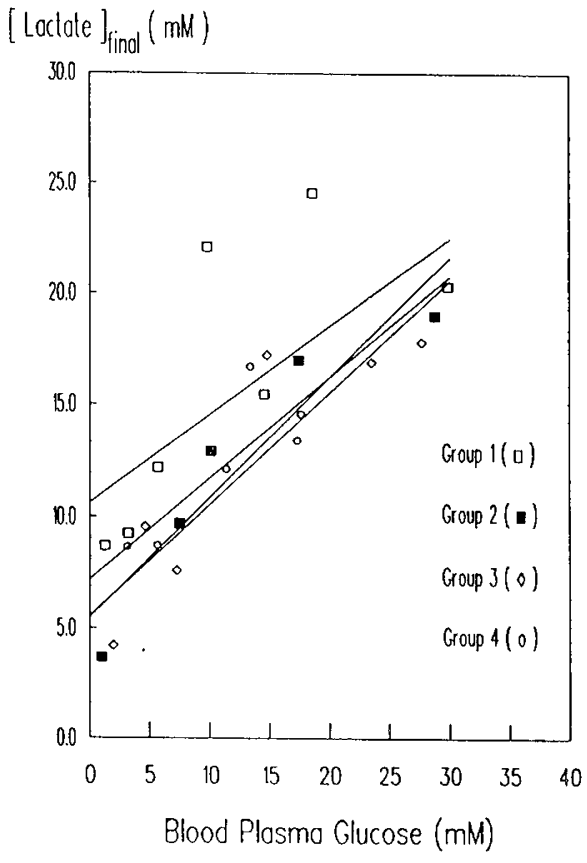

Fig. 4. The relationship between maximal brain lactate concentration and blood plasma glucose concentration for different age groups of piglets. Different symbols are used to represent animals in each of the four age groups as previously defined (Table 1). The solid lines represent the best fit by linear regression analysis for each of the four age groups; the slopes $( \pm \mathrm{SD})$ for groups 1 to 4 are $0.46 \pm 0.21,0.54 \pm 0.13,0.50 \pm$ 0.13 , and $0.45 \pm 0.16 \mathrm{mM}$ lactate/mM glucose, respectively. Intercepts for groups 1 to 4 are $10.6 \pm 4.8,5.5 \pm 2.5,5.6 \pm 2.8$, and $7.2 \pm 2.0 \mathrm{mM}$ lactate, respectively.

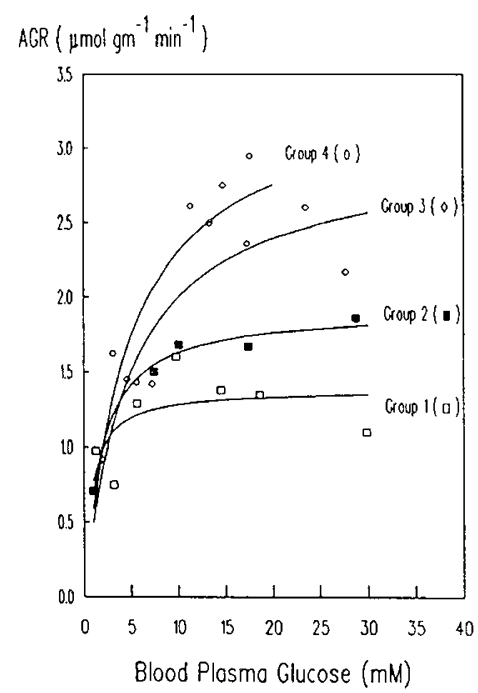

Fig. 5. Dependence of AGR upon plasma glucose concentration at the initiation of total ischemia. Different symbols are used to represent piglets of four different age groups (see Table 1). The solid lines represent the best fit by nonlinear regression to the data using equation 3 (Materials and Methods). The best fit $\mathrm{V}_{\max }$ and $\mathrm{Km}$ values are summarized in Table 2.

difference in $\mathrm{PCO}_{2}$ between group 1 and groups 2-4 would have a significant effect on the measured glycolytic rates.

In the present study, short-acting anesthetics were used during surgery so that by the time of the experiment their potential effects on cerebral metabolism would be negligible. The use of nalbuphine for analgesia during the NMR measurements of AGR are not expected to affect cerebral metabolism, inasmuch 
Table 2. Summary of maximum glycolytic rates $\left(V_{\max }\right)$ and apparent glucose affinity constants $(\mathrm{Km})$ for different age groups of piglets (best fit value $\pm S D$ )*

\begin{tabular}{lllll}
\hline & Group 1 & Group 2 & Group 3 & Group 4 \\
\hline $\mathrm{V}_{\max }\left(\mu \mathrm{mol} \cdot \mathrm{g}^{-1} \cdot \mathrm{min}^{-1}\right)$ & $1.38 \pm 0.17^{2,3,4}$ & $1.92 \pm 0.064^{1,3,4}$ & $2.99 \pm 0.52^{1,2}$ & $3.42 \pm 0.65^{1,2}$ \\
$\mathrm{Km}(\mathrm{mM})$ & $0.79 \pm 0.70^{3,4}$ & $1.79 \pm 0.33^{3,4}$ & $4.96 \pm 2.90^{1,2}$ & $4.82 \pm 2.96^{1,2}$ \\
\hline
\end{tabular}

* The superscripts $1,2,3$, and 4 refer to the groups means that are significantly different from the group listed in the column heading at $p<0.05$ using the Duncan multiple comparison test.

as narcotic opiates can relieve pain but have no or only mild depressive effects on CNS activity (28).

An important finding from the present study is that the relative increase in AGR from normo- to hyperglycemia is not as great for newborn piglets compared with older piglets. For example, using the kinetic constants determined for newborn piglets (group 1 , Table 2) and assuming [glucose] $]_{\text {plasma }}$ equals $5 \mathrm{mM}$, we calculate an AGR value equal to $1.2 \mu \mathrm{mol} \cdot \mathrm{g}^{-1} \cdot \mathrm{min}^{-1}$. Now, if [glucose $]_{\text {plasma }}$ equals $20 \mathrm{mM}$, then an AGR value equal to $1.3 \mu \mathrm{mol}$. $\mathrm{g}^{-1} \cdot \mathrm{min}^{-1}$ is expected. In contrast, for 4-wk-old piglets (group 4), a similar increase in [glucose] $]_{\text {plasma }}$ would result in a larger increase in AGR from 1.7 and $2.8 \mu \mathrm{mol} \cdot \mathrm{g}^{-1} \cdot \mathrm{min}^{-1}$, respectively. The reason for the smaller relative increase in AGR for newborn piglets compared with older animals is readily apparent in Table 2 . The Km for newborn piglets is only $0.79 \mathrm{mM}$, compared with values of 5.0 to $4.8 \mathrm{mM}$ for 14 - to 30 -d-old piglets. This means that for newborns AGR will be within $10 \%$ of its maximal values $\left(\mathrm{V}_{\max }\right)$ when [glucose] $]_{\text {plasma }}$ is greater than $7 \mathrm{mM}$. The comparable [glucose $]_{\text {plasma }}$ value for 14 - to 30 -d-old piglets is greater than 40 $\mathrm{mM}$.

It is clear that for any given [glucose] $]_{\text {plasma, }}$ cerebral lactate accumulation rates in newborn piglets are substantially lower than in older animals. This point is best illustrated by calculating lactate accumulation, using equations 2 and 3 and the kinetic constants presented in Table 2 . For normoglycemic newborns (i.e. $5 \mathrm{mM}$ [glucose] $]_{\text {plasma }}$ ), the initial rate of lactate accumulation is $2.4 \mu \mathrm{mol} \cdot \mathrm{g}^{-1} \cdot \mathrm{min}^{-1}$; the comparable value for 14 - to $30-\mathrm{d}-$ olds is 3.0 to $3.5 \mu \mathrm{mol} \cdot \mathrm{g}^{-1} \cdot \mathrm{min}^{-1}$. The difference in rates of lactate accumulation are even more pronounced at elevated [glucose] $_{\text {plasma }}$. For example, if [glucose] $]_{\text {plasma }}$ equaled $25 \mathrm{mM}$, then lactate accumulated at $2.7 \mu \mathrm{mol} \cdot \mathrm{g}^{-1} \cdot \mathrm{min}^{-1}$ for newborns compared with 5.0 to $5.7 \mu \mathrm{mol} \cdot \mathrm{g}^{-1} \cdot \mathrm{min}^{-1}$ for 14 - to $30-\mathrm{d}-\mathrm{old}$ piglets. The more pronounced effect at higher [glucose] $]_{\text {plasma }}$ levels is explained at least in part by the tendency in newborns for $\mathrm{k}$ to decrease as [glucose] piglets $\mathrm{k}$ does not change as a function of [glucose $]_{\text {plasma }}$ (Fig. 3). Assuming a blood plasma glucose concentration of $25 \mathrm{mM}$ and a steady state of lactate production, the proposed critical threshold for brain lactate concentration associated with irreversible tissue damage $\left(20 \mu \mathrm{mol} \cdot \mathrm{g}^{-1} \cdot \mathrm{min}^{-1}\right.$ for adults; see introduction), would be reached in about $7 \mathrm{~min}$ in newborns compared with 3.7 to $3.2 \mathrm{~min}$ in 14 - to 30 -d-old piglets. These calculations illustrate that the potential for newborn piglets to be less prone to brain lactosis compared with their older counterparts is due to their slower AGR. However, the [lactate] $]_{\text {final }}$ attained after 30 min was virtually the same for all four age groups of piglets (Fig. 4). The critical factor determining [lactate $]_{\text {final }}$ was the pre-cardiac arrest plasma glucose concentration, not animal age. The strong dependence of [lactate $]_{\text {final }}$ on [glucose $]_{\text {plasma }}$ is consistent with our early findings using a partial ischemia model, where a strong correlation was seen between intracellular $\mathrm{pH}$ and plasma glucose concentration $(14,15)$.

It is important to note that this study does not address the issues of whether hyperglycemia during ischemia enhances brain damage in piglets or if there are differences in the degree of damage related to age. At present there is no information available about glucose-mediated susceptibility toward ischemic brain injury in swine or any newborn species except rats (see introduction). However, the present data allow us to pose a working hypothesis that could be used to explore this issue for swine. If we accept the premise that acidosis during ischemia is detrimental to brain cell viability, then from the analysis presented above we would hypothesize that for a short ischemic insult (e.g. 10 min) newborn piglets should be less susceptible to injury than older piglets because lactic acid would accumulate more slowly. However, for an insult of longer duration (e.g. $30 \mathrm{~min}$ ) similar brain lactate levels will be generated regardless of age, implying that similar levels of brain injury will also occur regardless of age.

It needs to be emphasized that AGR measured in the present study is not the same as cerebral metabolic rate measured in the normal resting state by techniques such as positron emission tomography or autoradiography. The latter measurements have shown no relationship between cerebral metabolic rate and [glucose $]_{\text {plasma }}$ provided that there is normal oxygen and glucose delivery to the brain. However, under "agonal" conditions such as total ischemia, oxygen and glucose delivery is terminated and there is a rapid increase in the rate of glycolysis. Our findings are consistent with results from adult rabbits in that the AGR is strongly linked to [glucose] $]_{\text {plasma }}$ at the time cardiac arrest is initiated (18). As pointed out by Petroff et al. (18), the correlation between AGR and carbohydrate levels has not been studied because accurate time course data are difficult to obtain with destructive techniques that supply only one point per animal. This has important implications for the comparison to follow of our results to previous measurements of AGR in other species.

There are several literature reports of AGR measured in rodents of various ages. However, in a number of cases [glucose] plasma was either not measured or not reported, and we have assumed that [glucose] al. (29) estimated AGR by freezing the brains of mice and measuring brain lactate concentrations at eight different times after decapitation (29). Presumably [glucose] $]_{\text {plasma }}$ was the same for all these animals, although no values were reported. AGR was determined to be $6.5 \mu \mathrm{mol} \cdot \mathrm{g}^{-1} \cdot \mathrm{min}^{-1}$ in adults and 1.9 $\mu \mathrm{mol} \cdot \mathrm{g}^{-1} \cdot \mathrm{min}^{-1}$ in 10 -d old mice. In a separate study, 4- to $12-$ $\mathrm{h}$-old mice were reported to have an AGR of $0.7 \mu \mathrm{mol} \cdot \mathrm{g}^{-1}$. $\min ^{-1}(30)$. Regardless of age, the predecapitation glycolytic rate was estimated to be about 10 times lower than AGR, and the rapid increase in lactate after decapitation (or cardiac arrest as performed in the present study) suggests that cerebral glycolytic rate is accelerated within seconds after the onset of ischemia. AGR measured for term newborn, 1-d, and 7-d-old rats were $0.42,0.23$, and $0.97 \mu \mathrm{mol} \cdot \mathrm{g}^{-1} \cdot \mathrm{min}^{-1}$, respectively (31). Thus, AGR values for rodents appear lower than for normoglycemic (i.e. $\left.[\text { glucose] }]_{\text {plasma }}=5-6 \mathrm{mM}\right)$ newborn piglets $(\mathrm{AGR} \cong 1.2$ based on results for group 1; Fig. 5). It is possible that this could reflect greater brain maturation in newborn piglets compared with rodents. However, this conclusion is speculative because none of the above rodent studies specifically reports blood glucose concentrations at the time of decapitation. If AGR showed a similar dependence on glucose in rodents as found here for piglets, then hypoglycemia might account for the lower values of AGR in newborn rodents compared with newborn piglets. Indeed, blood glucose levels of about $4.5 \mathrm{mM}$ in newborn rats have been reported (32), supporting the possibility that the rodents studied in references 26 and 27 had low [glucose] plasma $_{\text {at }}$ at the time AGR was measured. Thus, without knowledge of [glucose $]_{\text {plasma }}$ and the kinetic parameters, $\mathrm{Km}$ and $\mathrm{V}_{\max }$ for newborn rodents, we cannot deduce whether AGR or glucose transport across the 
blood brain barrier is intrinsically higher for piglets compared with rodents. Similarly, there is insufficient information to use low glycolytic activity in immature rats as the explanation for the results of Vannucci et al. (11), that glucose supplementation has no effect on the concentration of brain lactate accumulated (11-19 $\left.\mu \mathrm{mol} \cdot \mathrm{g}^{-1}\right)$. In that study, rats were exposed to hypoxiaischemia for $2 \mathrm{~h}$, during which time [glucose] $]_{\text {plasma }}$ underwent substantial declines. Furthermore, there was still the potential for cerebral oxygen delivery because both $\mathrm{PO}_{2}$ and cerebral blood flow were non-zero (11). Thus, a substantial fraction of cerebral energy demand could be met by oxidative phosphorylation, resulting in nonmaximal acceleration of the glycolytic rate and therefore, nonmaximal brain lactate concentrations. In addition, continued blood flow may have contributed to the removal of lactate generated in the brain. It is of interest to note that nearterm fetal rats exposed to complete ischemia via placental clamping generate brain lactate concentrations as high as $29 \mu \mathrm{mol} \cdot \mathrm{g}^{-1}$ over a 30 -min period (33). This implies that immature rats have the same potential as piglets to generate high brain lactate concentrations, provided that the ischemic insult is severe and long enough.

A number of questions still need to be answered before we will understand the role of brain lactic acidosis in the evolution of neonatal brain damage. The present study shows that initial AGR is dependent on both age and blood glucose, whereas absolute concentrations of cerebral lactate formed after $30 \mathrm{~min}$ depend on plasma glucose concentration only. Strictly speaking, this conclusion applies only to the type of insult studied here, i.e. total cerebral ischemia. It is unclear what happens to cerebral glycolytic rates and glucose transport during different combinations of hypoxia-ischemia, hypercarbia, or hypocarbia. The type of protocol used in the present study is amenable to the study of these physiologic factors, inasmuch as circulatory arrest rapidly converts the brain into a closed system that initially reflects the physiologic conditions, such as blood $\mathrm{O}_{2}$ tension, and glucose concentrations, prevailing at the time cerebral perfusion is ceased.

A remaining question is whether the age-related changes in AGR measured in this study could be a reflection of maturational changes in the rate of glucose transport across the blood brain barrier. The key controlling enzymes, hexokinase and phosphofructokinase, are thought to be activated during ischemia, resulting in an increased glycolytic rate (29). However, under conditions of a greatly accelerated glycolytic rate, the potential exists that glucose transport into the brain could limit glycolysis (34, 35). The transport of ${ }^{14} \mathrm{C}$-glucose into the brain of adult versus suckling rats has been compared using both single injection (36) and steady state methods (37). Both experiments indicate a doubling in $\mathrm{V}_{\max }$ from 2 to $3 \mathrm{wk}$ of age $(0.52$ and $0.90 \mu \mathrm{mol}$. $\left.\mathrm{g}^{-1} \cdot \mathrm{min}^{-1}\right)$ to adulthood $\left(1.32\right.$ and $\left.2.23 \mu \mathrm{mol} \cdot \mathrm{g}^{-1} \cdot \mathrm{min}^{-1}\right) . \mathrm{Km}$ did not show any obvious change with age (range: 8 to $13 \mathrm{mM}$ ). Analogous studies on any other species apparently have not been done. The $\mathrm{V}_{\max }$ and $\mathrm{Km}$ values reported in Table 2 differ from $\mathrm{V}_{\max }$ and $\mathrm{Km}$ quoted from the above two rodent studies in one important respect. The latter two studies $(36,37)$ measured the cerebral uptake rate of radioactively labeled glucose by rapid fixation of the brain to trap the label within 10 to $60 \mathrm{~s}$ after the injection of ${ }^{14} \mathrm{C}$-glucose. However, in the present study, glucose uptake and utilization are measured after a 20 -min period when [glucose] $]_{\text {plasma }}$ was changed and after an additional 5 to $10 \mathrm{~min}$

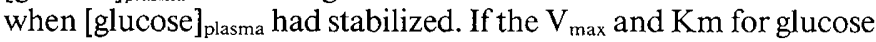
transport for piglets are similar to the values quoted above for rodents, then this period of time should have been sufficient to allow equilibration of glucose across the blood-brain barrier. Therefore, it would follow that the measured AGR would be independent of glucose transport and the $V_{\max }$ and $\mathrm{Km}$ values in Table 2 would reflect age-related changes in the rate-limiting reaction for the conversion of glucose to lactate during ischemia.

Acknowledgment. The authors thank the Department of Pe- diatrics for its continuing support, which made this study possible. We thank Dr. Rusty Gitomer for his careful review of this manuscript.

\section{REFERENCES}

1. Volpe JJ 1987 Hypoxic-ischemic encephalopathy: basic aspects and fetal assessment. In: Volpe JJ (ed) Neurology of the Newborn. WB Saunders, Philadelphia, pp 160-195

2. Myers RE 1979 Lactic acid accumulation as cause of brain edema and cerebral necrosis resulting from oxygen deprivation. In: Korobkin R, Guilleminault C (eds) Advances in Perinatal Neurology. Spectrum, New York, pp 85-114

3. Siemkowicz E, Anker JH 1978 Clinical restitution following cerebral ischemia in hypo-, normo- and hyperglycemic rats. Acta Neurol Scand 58:1-8

4. Pulsinelli W, Waldman S, Rawlinson D, Plum F 1982 Moderate hyperglycemia augments ischemic brain damage: a neuropathologic study in the rat. Neurology 32:1239-1246

5. Siesjo BK 1985 Acid-base homeostasis in the brain: physiology, chemistry, and neurochemical pathology. Prog Brain Res 63:121-154

6. Rehncrona S 1985 Brain acidosis. Ann Emerg Med 14:770-776

7. Hochachka PW, Mommsen TP 1983 Protons and anaerobiosis. Science 219:1391-1397

8. Helgason CM 1988 Blood glucose and stroke. Stroke 19:1049-1053

9. Selle WA 1944 Influence of glucose on the gasping pattern of young animals subjected to acute anoxia. Am J Physiol 141:297-302

10. Holowach-Thurston J, Hauhart RE, Jones EM 1974 Anoxia in mice: reduced glucose in brain with normal or elevated glucose in plasma and increased survival after glucose treatment. Pediatr Res 8:238-243

11. Vannucci RC, Vasta F, Vannucci SJ 1987 Cerebral metabolic responses of hyperglycemic immature rats to hypoxia-ischemia. Pediatr Res 21:524-529

12. Vannucci RC 1990 Experimental biology of cerebral hypoxia-ischemia: relation to perinatal brain damage. Pediatr Res 27:317-326

13. Vannucci RC 1989 Acute brain injury: hypoxic-ischemia. In: Cohen WR, Acker DB, Friedman EA (eds) Management of Labor. Aspen, Rockville, MD, pp 183-244

14. Corbett RJT, Laptook AR, Nunnally RL, Hassan A, Jackson J 1988 Intracellular $\mathrm{pH}$, lactate, and energy metabolism in neonatal brain during partia ischemia measured in vivo by ${ }^{31} \mathrm{P}$ and ${ }^{1} \mathrm{H}$ nuclear magnetic resonance spectroscopy. J Neurochem 51:1501-1509

15. Laptook AR, Corbett RJT, Nunnally RL 1990 Effect of plasma glucose concentration on neonatal cerebral metabolism during partial ischemia. Stroke 21:435-440

16. Linderkamp O, Betke K, Guntner M, Jap GH, Riegel KP, Walser K 1981 Blood volume in newborn piglets: effects of time of natural cord rupture intra-uterine growth retardation, asphyxia, and prostaglandin-induced prematurity. Pediatr Res 15:53-57

17. Gonnella NC, Silverman RF 1989 Design and construction of a simple double tuned single input surface coil probe with multinuclear capability. Soc Magn Res Med 2:948(abstr)

18. Petroff OAC, Prichard JW, Ogino T, Shulman RG 1988 Proton magnetic resonance spectroscopy studies of agonal carbohydrate metabolism in rabbit brain. Neurology 38:1569-1574

19. Hore PJ 1983 Solvent suppression of Fourier transform nuclear magnetic resonance. J Magn Res 55:283-300

20. Corbett RJT, Laptook AR 1990 Acid homeostasis and partial ischemia in neonatal piglet brain. J Neurochem 54:1208-1217

21. Gyulai L, Schnall M, McLaughlin AC, Leigh JS, Chance B 1987 Simultaneous ${ }^{31} \mathrm{P}$ - and ${ }^{1} \mathrm{H}$ nuclear magnetic resonance studies of hypoxia and ischemia in cat brain. J Cereb Blood Flow Metab 7:543-551

22. Corbett RIT, Laptook AR, Nunnally RL 1987 The use of the chemical shift of the phosphomonoester P-31 magnetic resonance peak for the determination of intracellular pH in the brains of neonates. Neurology 37:1771-1779

23. Cunningham VJ, Sarna GS 1979 Estimation of the kinetic parameters of unidirectional transport across the blood brain barrier. $J$ Neurochem 33:433437

24. Cleland WW 1967 The statistical analysis of enzyme kinetic data. Adv Enzymol Relat Areas Mol Biol 29:1-32

25. Duncan DB 1955 Multiple range and multiple $F$ tests. Biometrics 1 1:1-42

26. Miller AL 1985 Carbon dioxide narcosis. In: McCandless DW (ed) Cerebral Energy Metabolism and Metabolic Encephalopathy. Plenum Press, New York, pp 143-162

27. Corbett RJT 1990 In vivo multinuclear magnetic resonance spectroscopy investigations of cerebral development and metabolic encephalopathy using animal models. Semin Perinatol 14:258-271

28. Benedetti C, Butler SH 1990 Systemic analgesia. In: Benica JJ (ed) The Management of Pain, Vol II. Lea \& Febiger, Philadelphia, pp 1640-1675

29. Lowry OH, Passonneau JV, Hasselberger FX, Schultz DW 1964 Effect of 
ischemia on known substrates and cofactors of the glycolytic pathway in brain. J Biol Chem 239:18-30

30. Holowach-Thurston J, McDougal DB 1969 Effect of ischemia on metabolism of the brain of the newborn mouse. Am J Physiol 216:348-352

31. Duffy TE, Kohle SJ, Vannucci RC 1975 Carbohydrate and energy metabolism in perinatal rat brain: relation to survival in anoxia. J Neurochem $24: 271-$ 276

32. Vannucci RC, Duffy TE 1976 Carbohydrate metabolism in fetal and neonatal rat brain during anoxia and recovery. Am J Physiol 230:1269-1275

33. Magal E, Goldin E, Harel S, Yavin E 1988 Acute uteroplacental ischemic embryo: lactic acid accumulation and prostaglandin production in the fetal rat brain. J Neurochem 51:75-80
34. Lund-Andersen H 1979 Transport of glucose from blood to brain. Physiol Rev 59:305-352

35. Bachelard HS 1983 Transport of hexoses and monocarboxylic acids. In: Lajtha A (ed) Handbook of Neurochemistry, Vol 6, 2nd Ed. Plenum Press, New York, pp 339-354

36. Cremer JE, Cunningham VJ, Pardrige WM, Braun LD, Oldendorf WH 1979 Kinetics of blood brain barrier transport of pyruvate, lactate and glucose in suckling, weanling, and adult rats. J Neurochem 33:439-445

37. Daniel PM, Love ER, Pratt OE 1978 The effect of age upon the influx of glucose into the brain. J Physiol 274:141-148

\section{Announcements}

\section{Meeting Announcement}

The International Federation for Juvenile and Infantile Gynecology will hold its 10th World Congress of Pediatric and Adolescent Gynecology in Paris, France from May 21 through May 23, 1992. For further information and registration, contact: Convergences Gyn-Juv 92, 120 Avenue Gambetta, F-75020 Paris, France, FAX: (33) 1-40-31-01-65.

\section{9th Annual Seminar in Pediatric Nephrology}

The 19th Annual Seminar in Pediatric Nephrology; Current Concepts in Diagnosis and Management will be held February 9-13, 1992 at the Sheraton Royal Biscayne Beach Resort and Racquet Club, Key Biscayne, FL. For further information, contact: Jose Strauss, M.D., University of Miami School of Medicine, Department of Pediatrics, P.O. Box 016960, Miami, FL 33101, (305) 549-6726. 